\title{
Discovering hidden time patterns in behavior: T-patterns and their detection
}

\author{
MAGNUS S. MAGNUSSON \\ University of Iceland, Reykjavik, Iceland
}

\begin{abstract}
This article deals with the definition and detection of particular kinds of temporal patterns in behavior, which are sometimes obvious or well known, but other times difficult to detect, either directly or with standard statistical methods. Characteristics of well-known behavior patterns were abstracted and combined in order to define a scale-independent, hierarchical time pattern type, called a T-pattern. A corresponding detection algorithm was developed and implemented in a computer program, called Theme. The proposed pattern typology and detection algorithm are based on the definition and detection of a particular relationship between pairs of events in a time series, called a critical interval relation. The proposed bottom-up, level-by-level (or breadth-first) search algorithm is based on a binary tree of such relations. The algorithm first detects simpler patterns. Then, more complex and complete patterns evolve through the connection of simpler ones, pattern completeness competition, and pattern selection. Interindividual T-patterns in a quarter-hour interaction between two children are presented, showing that complex hidden T-patterns may be found by Theme in such behavioral streams. Finally, implications for studies of complexity, self-organization, and dynamic patterns are discussed.
\end{abstract}

Hidden or nonobvious temporal patterns in behavior are of long-standing interest in various areas of behavioral research: "Behavior consists of patterns in time. Investigations of behavior deal with sequences that, in contrast to bodily characteristics, are not always visible" (EiblEibesfeldt, 1970, p. 1, emphasis added). Integrated studies of the structure of verbal and nonverbal behavior have been repeatedly proposed (Pike, 1960; Skinner, 1957): "The activity of man constitutes a structural whole, in such a way that it cannot be subdivided into neat "parts" or "levels" or "compartments" insulated in character, content, and organization from other behavior. Verbal and nonverbal activity is a unified whole, and theory and methodology should be organized or created to treat it as such" (Pike, 1960, p. 2).

Such an approach requires sufficient knowledge about recurrent patterns in observable behavior. However, these patterns may be hidden and difficult to detect without adequate tools. This paper concerns some of these methodological difficulties and proposes some solutions.

This work was supported by Icelandic Research Council Grants 95140,96058 , and 97163 . Special thanks for invaluable support go to J. Beaudichon, University of Paris V-Sorbonne; S. Duncan, University of Chicago; R. Ghiglione, University of Paris XIII; A. Langaney, M.N.H.N., Paris; H. Montagner, INSERM, France; and M. Lyon, S. K. Moeller, and S. Ross, University of Copenhagen. A free executable version (not source code) of the Theme program is available on line (www.hi.is/ msm), but at the time of this writing, it is hoped that a more powerful commercial version will soon be available from a company (PatternScope) that is now being created by the author and lcelandic Venture Funds (see www.hi.is/ msm for up-to-date information). Correspondence concerning this article should be addressed to M. S. Magnusson, Human Behavior Laboratory, University of Iceland, Sudurgata 26, IS-101 Reykjavik, Iceland (e-mail: msm@rhi.hi.is).
The present work began with a study of children's social interaction and was aimed at the detection of nonobvious or hidden probabilistic interaction sequences, such as had been discovered in both children's and adult's dyadic interactions (see, notably, Duncan \& Fiske, 1977; Montagner, 1978). With gradually improved pattern definitions and detection algorithms, unexpectedly complex and regular repeated patterns emerged (Magnusson, 1982, $1983,1988,1989,1996,1998)$. Different versions of the resulting software (Theme; see Appendix E) have already been used in a number of studies (notably, Beaudichon, Legros, \& Magnusson, 1991; Blanchet \& Magnusson, 1988; Grammer, Kruck, \& Magnusson, 1998; Lyon, Lyon, \& Magnusson, 1994; Lyon \& Magnusson, 1982; Magnusson \& Beaudichon, 1997; Montagner et al., 1990).

\section{THE PROPOSED PATTERN TYPE}

Even though unaided observers often perceive human behavior in interactions as somewhat structured and repetitive, they find it difficult or impossible to specify what kinds of patterns are being repeated or when. The approach adopted here, therefore, assumes that the temporal structure of a complex system of behavior is largely unknown, at least consciously. Thus, ideas or hypotheses are needed concerning kinds of patterning for which detection methods must then be found, adapted, or created.

\section{Roots and Application Possibilities}

The kind of pattern proposed below is called a T-pattern, to distinguish it clearly as being just one particular kind of temporal pattern or configuration, which, together with the corresponding detection algorithm, might be most readily used in areas close to its conceptual and method- 
ological origin. Essential in this respect are the probabilistic, real-time contingency, stimulus control (Skinner, 1969), and mand concepts (Skinner, 1957) of radical behaviorism and the linguistic concept of syntactic structure in the repeated surface patterns of speech (notably, Chomsky, 1959, 1965). Neither of these authors, however, provided a methodology for the integrated study of complex verbal and nonverbal behavior and interactions in natural settings.

The detection of hidden recurrent action patterns and probabilistic social interaction sequences in natural or relatively unconstrained settings is a common goal of ethological research (Dawkins, 1976; Montagner, 1978; Tinbergen, 1963) and of human interaction research, such as the analysis of turn taking (Duncan \& Fiske, 1977).

Perceptual grouping of stimuli according to proximity and form is well known from Gestalt psychology (Köhler, 1947), but the ease with which such grouping breaks down in the presence of noise (i.e., other concurrent stimuli) is here a central issue (see below). In music, the repetition (not necessarily cyclical) of rhythmic phrases, melodies, and themes, sometimes undetectable (at least consciously) by untrained listeners, confirms the possible existence of such hidden patterns and, thereby, the importance of time in human behavior organization.

A treatment of these relations is, however, outside the scope of this paper. Nor is it absolutely necessary, because patterns in everyday behavior may serve directly as models for the definition of the T-pattern (and its derived types) without necessary implication of other viewpoints. This is sometimes fortunate, since irrelevant or unnecessary theoretical considerations are avoided when the method is applied in other areas. Thus, analysis using this method is objective and operationalized, so it requires no prior commitment to a particular theoretical viewpoint. The T-pattern type and detection algorithm will, therefore, be explained and defined by using everyday pattern examples and in verbal, graphical, and formal ways, beginning with looser definitions, which are gradually restricted and formalized.

\section{From Well-Known Patterns to T-Patterns}

Behind the pattern definition lie the hypothesis that both hidden and manifest behavior patterns may involve similar relations among their parts. The T-pattern definition, therefore, attempts to abstract some of these relations in order to create an algorithm for the detection of hidden patterns. Examples of well-known patterns that may serve as models are, for example, standard phrases, which are sequences of words that, in turn, are sequences of phonemes. Verbal examples are "How do you do?" or "If . . . then ... else ....." the latter with open slots (marked by ...) that may be filled in various ways. Patterns with both verbal and nonverbal components include greeting rituals and a multitude of other everyday ceremonies, routines, and processes of work and play. For example, a lunch is a pattern that typically involves simpler behavioral components that are themselves patterns-that is, sitting down at a table, eating the main course, having a desert, drinking coffee, and then standing up from a table. Each of the component patterns is again composed of simpler behavioral components that may also be patterns of the same kind. Thus, for example, sitting down at a table typically involves pulling a chair out from a table (which includes reaching out and pulling), moving in front of the chair (which also includes a series of movements), and then bending the knees to lower the trunk. Each of these subpatterns may also occur alone or as part of various other patterns. (Other examples, from music performance, are various repeated rhythmic phrases, melodies, and themes, often composed of simpler ones and, finally, of simple beats or nodes separated by time intervals.)

Between the components of a T-pattern, the number and type of behaviors that may occur may vary greatly from instance to instance of the same pattern, which makes the detection of such patterns difficult with methods that depend only on the order or sequence of events.

It is such recurring hierarchically organized patterns (i.e., patterns of patterns of patterns, etc.) of verbal and/or nonverbal behaviors, whether intra- and/or interindividual, that are the principal models for the proposed pattern type.

\section{Causality}

Sometimes, a pattern of this kind involves a causal relation - that is, an earlier part of the pattern may be seen as a likely cause of a later part of the same pattern, as, for example, in the interindividual pattern "How do you do? Very well, thank you," where the intraindividual preceding part ("How do you do?") is a likely cause of the consequent occurrence of the other intraindividual pattern ("Very well, thank you") performed by a different individual. In other cases, the relations may be more like those between the words within an intraindividual pattern, such as "Very well, thank you," where an earlier word is usually not considered to be a cause of any word following it within the pattern.

\section{The Critical Interval and Pattern Detection}

Of essential interest here are some relations between the distributions of components of a T-pattern. Thus, over the repeated occurrences of a particular T-pattern, its components occur in the same order each time, and, moreover, each of the consecutive time distances separating consecutive components remains relatively invariant - that is, relative to an expectation assuming, as a null hypothesis, that each component is independently and randomly distributed over time with its observed average frequency.

Making use of real-time information, the following probabilistic real-time relation, which follows from this T-pattern definition and null hypothesis, here serves as a $k e y$ to the detection of hidden T-patterns. That is, if $\mathrm{A}$ is an earlier and $\mathrm{B}$ a later component of the same recurring $\mathrm{T}$ pattern, then, after an occurrence of $A$ at $t$, there is an interval $\left[t+d_{1}, t+d_{2}\right]\left(d_{2} \geq d_{1} \geq 0\right)$ that tends to contain at least one occurrence of $B$ more often than would be 

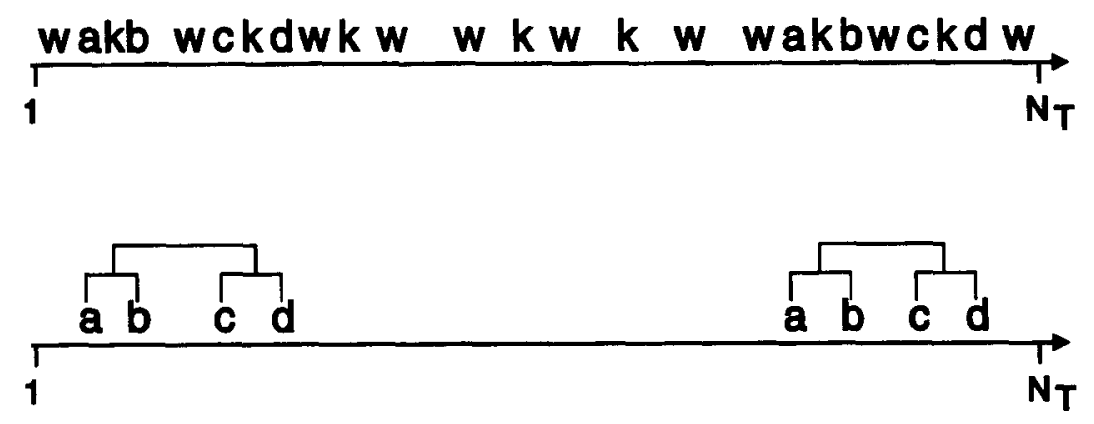

\begin{abstract}
Figure 1. The upper part of this figure shows a simple real-time behavior record containing the occurrences of a few types of events- that is, $A, B, C, \ldots$-with the lowercase letters $(a, b, c, \ldots)$ indicating their respective instances within the observation period $[1$, $N_{T}$ ]. The lower part (line) is identical to the upper one, except that all occurrences of $K$ and $W$ have been removed. $A$ simple $T$-pattern $(A B C D)$ then appears, which was difficult to see when the other events were present (even after it had been pointed out). One possible binary tree $((A B)(C D))$ is shown, but others, such as $((A(B C)) D)$ or $(A((B) C D))$ are possible (see the text).
\end{abstract}

expected by chance. This relation is here called a critical interval (or $\mathrm{CI}$, more precisely defined below) relation between the distributions of $\mathrm{A}$ and $\mathrm{B}$ and is essential for the more formal definitions of the T-pattern type and its detection algorithm, given below.

\section{Missing Components}

The later component, $\mathrm{B}$, need not be the one immediately following $\mathrm{A}$ within the pattern, so even when some elements of a T-pattern are ignored (e.g., not coded or unknown), it may still have the defining characteristics of a T-pattern, albeit a less complete one. This is obviously important when searching for hidden patterns in complex behavioral streams with a largely unknown temporal structure and may also help to explain why some detected patterns can be hard to interpret (understand).

\section{REASONS FOR FOCUSING ON THE T-PATTERN TYPE}

One reason for focusing on this pattern type is its widespread occurrence in various kinds of behavioral streams and at highly different time scales, suggesting its importance in the organization of behavior. A further reason is that these patterns easily become invisible to the naked eye when other behavior occurs in parallel with them, as is typically the case (see Figure 1). Moreover, patterns of this kind may often be hard or impossible to detect with the well-known statistical methods that are found in major statistical program packages and behavior research software, such as The Observer (Noldus, 1991; Noldus et al., 2000) or GSEQ (Bakeman \& Quera, 1995). Taken together, these reasons might partly explain why this particular pattern type has not received more attention.

\section{METHOD}

The proposed T-pattern detection algorithm is based on a more precise and restricted T-pattern definition, which refers to a particular data structure and involves the CI relationship, as well as a competition between patterns in which only the most complete patterns survive.

\section{THE BEHAVIOR RECORD OR DATA TYPE}

Behavior is coded during an observation period $\left[1, N_{T}\right]$ in terms of the discrete occurrence times of event types, where each event type is the beginning or ending of some particular behavior performed by a particular agent. The behavior is described in terms of such categories as runs, laughs, talks, stands, smiles, and so forth, with optional qualifiers such a fast, slow, left, nonverbally, and so forth. For example, bill,e,run,fast (Bill ends running fast) and sue,b,smile (Sue begins to smile) are two different event types (see also Appendix D).

Each event type occurrence is located at a time unitthat is, is a point on a discrete time scale. Thus, its occurrence times series, $S$, is a series of integer values within $\left[1, N_{T}\right]$. This kind of series is herein called a simple series. Although each event type thus either occurs or not ( 0 or 1$)$ within each discrete time unit, any number of the different event types may occur within the same time unit.

All the definitions below thus refer to behavior records that consist exclusively of an arbitrarily ordered set of $K$ different event types, $E_{1 \ldots K}$, each with its simple series, $S_{i}$, of discrete occurrence times observed within the observation period $\left[1, N_{T}\right]$. That is, Data $=D=\left\{(E, S)_{1 \ldots K}\right.$, $\left.\left[1, N_{T}\right]\right\}$ defines the data set completely.

\section{Categories of Different Kinds}

Categories are usually behavioral but may also be physiological and/or environmental or any mixture of all of these. But the choice of categories and time scale must be based on a good understanding of the system being studied, as well as of the T-pattern type and the detection algorithm.

Data may, of course, be collected either automaticallyfor example, from Skinner boxes or physiological mea- 
surement devices —or through (manual) coding. Adequate chronological data collected by various institutions and involving quite different time scales may also be availablefor example, concerning economical transactions or health history-and the analysis of such data has just begun at this laboratory.

\section{Different Dimensions}

Although the one-dimensional (1-D) T-pattern type was initially developed with real time in mind, it may be applicable to other kinds of 1-D data. For example, real time may sometimes be fairly well approximated by (ordinal) event time, and a spatial dimension replaces time in attempts (just begun at this laboratory) to detect T-patterns in DNA. The generalization of the T-pattern and its detection algorithm to two-dimensional, three-dimensional, and even $N$-dimensional data is in preparation.

\section{T-PATTERN DEFINITION}

The definitions given below refer exclusively to the kind of behavior record, $D$, defined above. However, to simplify the formal T-pattern definition, event types are per definition considered as T-patterns (the simplest possible).

Thus, the T-pattern can be (still somewhat loosely) defined, recursively, as a recurring ordered set $Q=X_{1} \approx d t_{1}$ $X_{2} \approx d t_{2} \ldots X_{i} \approx d t_{i} X_{i+1} \ldots X_{m}$ (short $\left.X_{1} \ldots X_{m}\right)$, where the $X$ terms stand for simpler T-patterns and each $\approx d t$ term $\left(\approx d t_{i} \geq 0\right)$ stands for a relatively invariant time distance separating the consecutive $X_{i}$ and $X_{i+1}$ terms within occurrences of $Q$. As before, relatively invariant means relative to random expectation, given the null hypothesis that all $X$ terms are independently and randomly distributed with their observed frequencies, but this notion is given a more precise definition below. The general term $X_{i} \approx d t_{i} X_{i+1}$ thus reads: (within occurrences of the pattern) when pattern $X_{i}$ ends, it is followed $\approx d t_{i}$ time units later by the beginning of pattern $X_{i+1}$.

The different $\approx d t$ terms of any particular pattern may have very different average values, but each varies within a particular interval. The $\approx d t$ terms may, thus, be replaced by these intervals, whereby the general T-pattern may be written $Q=X_{1}\left[d_{1}, d_{2}\right]_{1} X_{2}\left[d_{1}, d_{2}\right]_{2} \ldots X_{i}\left[d_{1}, d_{2}\right]_{i} X_{i}+$ $1 \ldots X_{m}$, where the general term $X_{i}\left[d_{1}, d_{2}\right]_{i} X_{i+1}$ reads: (within occurrences of the pattern) when pattern $X_{i}$ ends, then, between $d_{1}$ and $d_{2}$ time units, later pattern $X_{i+1}$ begins (see also the definition of a double series, below). This definition is further specified below, after some new terms have been defined.

\section{Double Versus Simple Occurrence Times Series}

The occurrence times of the first and the last event type of a T-pattern, $Q$, may be seen as a series of pairs of occurrence times (i.e., the occurrence times of $A$ and $D$ in the occurrences of the ABCD pattern in Figure 1) or as $a$ pair of simple series (i.e., the occurrences of $\mathrm{A}$ vs. those of $\mathrm{D}$ in $\mathrm{ABCD}$, Figure 1) written $Q_{i 1}$ and $Q_{i 2} ; i=1 \ldots N_{Q}$, where $N_{Q}$ is the number of occurrences of $Q$. The $i$ th oc- currence of $Q$ is thus said to begin at $Q_{i 1}$ and to end a $Q_{i 2}$. A double series may, thus, also be seen as a series o line segments on a discrete time scale. The beginnings an endings of occurrences of the same pattern must not $t_{1}$ be confused with the beginning and ending of behavior that define different event types in the behavior record.

As was already mentioned, an event type is conve niently thought of as a pattern, $Q$, involving only one even type. Its simple series is then considered as a (pseudo double series where $Q_{i 1}=Q_{i 2} ; i=1 \ldots N_{Q}$. In this way the occurrences points of event types can also be seen a line segments (of length one), and all simple series as th beginning or end points of such line segments. Conse quently, all T-patterns may then be seen as repeated pat terns of connected line segments, and detection as thi process of connecting line segments on the basis of $\mathrm{C}$ relations between the distributions of their beginning 0 end points.

\section{Free and Fast Critical Intervals}

The definition of the CI relationship is an attempt to de fine objectively what relatively invariant (or similar o: fixed) and relatively short distances between T-patter components mean, in a way that facilitates automatic de. tection of T-patterns. Although this relationship is hert essential for both the definition and the detection of $\mathrm{T}$. patterns, whether simple or complex, it only relates twc simple occurrence times series (each of which may have as little as two occurrence times) within an observatior period, $\left[1, N_{T}\right]$. Its definition follows.

Given (1) two simple occurrences series, $a_{i}$ and $b_{j}$, o event types $\mathrm{A}$ and $\mathrm{B}$, respectively, where $i=1 \ldots N_{\mathrm{A}}$ anc $j=1 \ldots N_{\mathrm{B}}$ and $N_{\mathrm{A}}$ and $N_{\mathrm{B}}$ are the number of occurrences of $A$ and $B$, respectively, within observation period [1. $\left.N_{T}\right]$, and (2) the null hypothesis that $\mathrm{A}$ and $\mathrm{B}$ are independently distributed and that the probability, $P(\mathrm{~B})$, of $\mathrm{E}$ occurring within any time unit is constant and equal tc $N_{\mathbf{B}} / N_{T}$ throughout the observation period [1, $\left.N_{T}\right]$.

Then, there is a free CI relationship, with $\mathrm{CI}\left[d_{1}, d_{2}\right]$ : between $\mathrm{A}$ and $\mathrm{B}$ if there is a series of intervals $\left[a_{i}+d_{1}\right.$. $\left.a_{i}+d_{2}\right] ; i=1 \ldots N_{\mathrm{A}}$, such that $k(k \geq 2)$ of these contain at least one instance of $\mathrm{B}$ and $k$ is significantly greater than expectation. Moreover, (1) significance is lost if $k$ is increased by extending $\left[d_{1}, d_{2}\right]$ - that is, by decreasing $d_{1}$ or increasing $d_{2}$-so that more intervals will include at least one $\mathrm{B}$ and (2) $k$ decreases if the size $\left[d_{1}, d_{2}\right]$ is reduced (increasing $d_{1}$ and/or decreasing $d_{2}$ ). In a word, the $\mathrm{CI}$ is the smallest possible $\left[d_{1}, d_{2}\right]$ interval that is significant while covering a maximum of cases $(k)$.

If $p$ remains significant when $d_{1}$ is set to zero, there is, per definition, also a fast $\mathrm{CI}$ relation.

Figures 2 and 3 illustrate this relationship. Figure 2 shows four minimal cases in which A and B occur only twice each within observation periods of the same length, whereas CI relations are found in only two cases (calculations are shown in Appendix B). In Case 2 of Figure 2, a significant $\mathrm{CI}$ is not found. Note, however, that had the observation lasted longer but no other instances of $\mathrm{A}$ or $\mathrm{B}$ oc- 


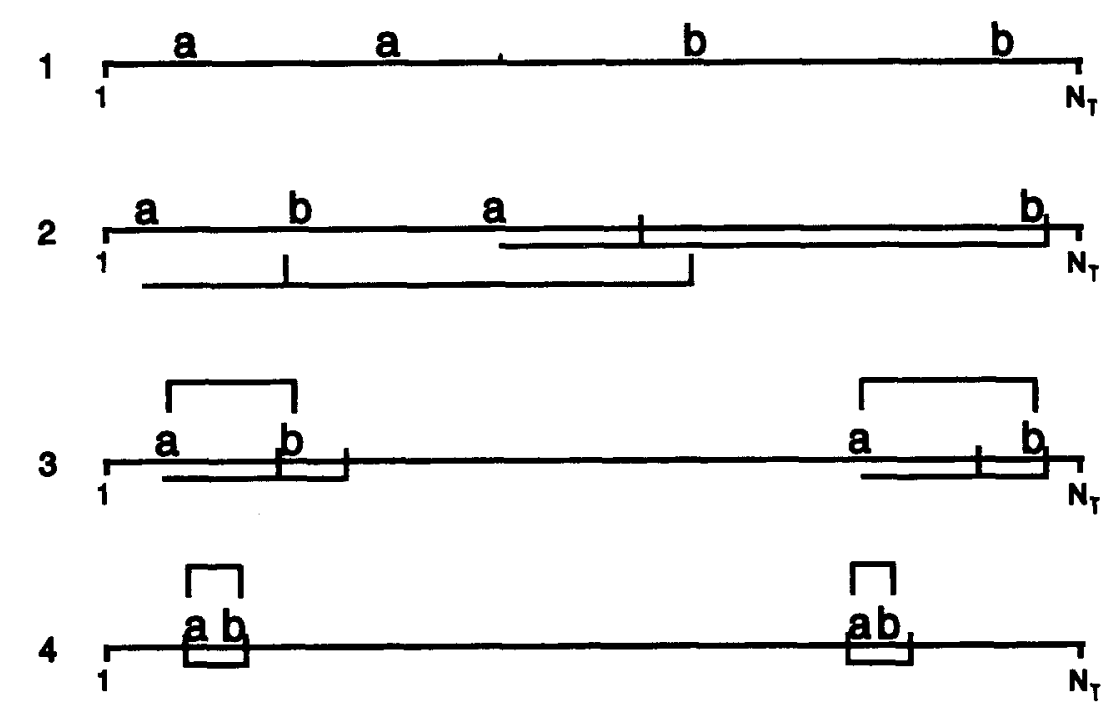

Figure 2. This figure shows four observation periods, [1, $\left.N_{r}\right]$, numbered 1 to 4 , each with two occurrences of each of two event types, $A$ and $B$. The only possible critical intervals (CIs) are shown, but in Case 2, it covers nearly half the observation period and is far from significant. In Case 3 , only a free $\mathrm{CI}$ is present, whereas in Case 4 , a fast $\mathrm{CI}$ is also present. See Appendix $B$ for calculations.

curred, the higher $N_{T}$ value could make the same interval significant, a CI which may seem strange, because the temporal distances have not changed (see Appendix A). Moreover, A and B might even represent, respectively, the beginning and the ending of the same behavior - such as, for example, running - but within a particular time horizon (observation period), the occurrence of B may still not be more predictable from $A$ than from a randomly chosen time point. That is, if the duration of the observed instances of running varies too much, relative to the length of the observation, no CI relation is present, even if the two event types are logically strongly related. Figure 3 shows a $\mathrm{Cl}$ relation, identical to that of Figure 4 (see below).

\section{Narrowing the T-Pattern Definition}

To facilitate a bottom-up detection strategy (see below), a recursive binary tree condition is added to the T-pattern definition. That is, for any T-pattern, there must be at least one way of splitting it into two consecutive $T$ patterns, $Q_{\text {Left }}\left(Q_{\mathrm{L}}\right)$ and $Q_{\text {Right }}\left(Q_{\mathrm{R}}\right)$; where $Q_{\mathrm{L}}$ precedes or is concurrent with $Q_{\mathrm{R}}$, with a CI relationship between the simple ending series of $Q_{\mathrm{L}}$ (written $Q_{\mathrm{L} i 2} ; i=1 \ldots N_{Q \mathrm{~L}}$ ) and the simple beginning series of the concurrent or following $Q_{\mathrm{R}}$ (written $Q_{\mathrm{R} j 1} ; j=1 \ldots N_{Q \mathrm{R}}$ ). Moreover, it must be possible to continue this splitting process recursively for both $Q_{\mathrm{L}}$ and $Q_{\mathrm{R}}$ until only pseudo-patterns (event types) are reached.
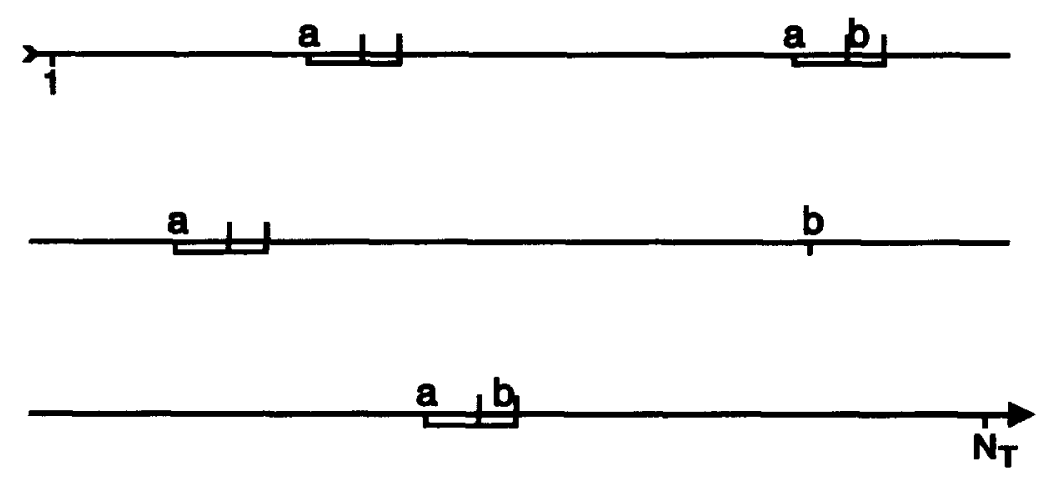

Figure 3. This figure illustrates the critical interval relation between the simple occurrence series $A$ and $B$. A short interval located at a fixed distance after occurrences of $A$ contains at least one occurrence of $B$ more often (here, only twice) than would be expected, assuming independent occurrences of $A$ and $B$ and a constant probability $P(B)=N_{B} / N_{T}$ of B occurring at each discrete time unit and assuming that $N_{T}$ is not too small (e.g., $N_{T}>100$ ). 


\section{Either Cyclical or Irregular Occurrences}

Although T-patterns may occur cyclically, this is not a part of their definition, and the distances between their occurrences may just as well be irregular.

\section{T-PATTERN DETECTION AND STANDARD STATISTICAL METHODS}

Despite the common everyday occurrence of T-patterns, statistical methods and software for their detection have been hard to find, since most available methods have been developed for different tasks. A treatment of the possibilities offered by such methods (alone or in combination) is obviously outside the scope of this paper, but some of their general characteristics, relative to the detection of Tpatterns, will be shortly noted below (at the risk of sometimes stating the obvious). It is assumed that the reader is familiar with behavioral analysis using statistical methods (see, e.g., Bakeman \& Gottman, 1997; Bakeman \& Quera, 1995; Colgan, 1978; Monge \& Cappella, 1980; Sackett, 1978; Scherer \& Ekman, 1982; Watt \& Vanlear, 1996).

Since the type of behavioral data in question is the occurrence times series of a multitude of qualitative phenomena, in very general terms, their multivariate character might suggest the use of standard multivariate statistics. However, these methods are generally aimed at the identification of clouds of points in multidimensional space, rather than of hierarchically ordered interval structures, such as T-patterns.

The temporal aspect of T-patterns might suggest the use of standard time series analysis for their detection, but these methods generally deal with cycles, waves, or trends and are, therefore, clearly not relevant for T-pattern detection, since they do not relate to any of their defining aspects.

The sequential and time lag aspect of T-patterns might suggest the use of standard lag sequential analysis techniques. But those using predefined fixed (time) lag windows are clearly not applicable when the temporal structure of a complex behavioral stream is largely unknown, and they do not deal well with the hierarchical, syntactical, or multi-ordinal aspect of T-patterns. Moreover, even if multi-ordinal sequential relations and automatically adapted time windows were added to these methods (going well beyond standard methods), a concept of repeated patterns similar to the T-pattern would still be missing. Therefore, in the presence of complex T-patterns, such methods might detect various sequential relations reflecting their existence, but without detecting them as such, which happened in the earliest versions of the algorithmthat is, before the T-pattern concept was defined and pattern evolution through competition and selection could be incorporated into the Theme algorithm (see below).

\section{T-PATTERN DETECTION}

The T-pattern detection algorithm described below mostly relies on extensive repetition of a few fast com- puter operations, and only simple statistics are involved (i.e., only elementary binomial probability theory), making the algorithm and its results relatively transparent. A similar wish for transparency is behind the creation of a special kind of diagram that, for each pattern, shows all the series (data) involved and how some of their points are connected to form the pattern (see below).

The number of possible T-patterns, even in a moderate data set, is very high. For example, when the number of event types is 100 , the number of T-patterns involving up to 10 event types is many orders of magnitude greater than $10^{11}$ if all possible time windows are also considered. Considering each separately is, thus, an impossible task, even for supercomputers. This is why, in accordance with the assumed hierarchical structure of T-patterns, a bottomup, level-by-level (or breadth-first) detection strategy is used by which simpler patterns are detected first, whereas more complex patterns are detected as patterns of simpler ones.

The two-stage bottom-up detection algorithm reverses the binary splitting procedure described above and is aimed at the detection of the longest possible T-patternsthat is, those involving the highest number of event types. The first stage deals with CI search and the construction of new patterns. The second stage deals with completeness competition, where all detected patterns that are less complete versions (i.e., one ore more components are missing) of some other detected pattern are dropped (see below).

\section{Stage 1: Search and Construction}

Beginning with the initial behavior record, the algorithm treats all possible pairs of the pseudo-patterns (i.e., the event types in the input data) as potential $Q_{\mathrm{L}}$ and $Q_{\mathrm{R}}$ parts of longer patterns. If it detects a $\mathrm{CI}$ relation, $\left[d_{1}, d_{2}\right]$, between $Q_{\mathrm{L}}$ and $Q_{\mathrm{R}}$ (i.e., between the simple ending series of $Q_{\mathrm{L}}$ and the simple beginning series of $\left.Q_{\mathrm{R}}\right)$, it constructs a new pattern, $Q=\left(Q_{\mathrm{L}} Q_{\mathrm{R}}\right)$.

An instance (occurrence) of the new pattern, $Q$, occurs each time an instance of $Q_{\mathrm{L}}$ ends at $t$ and an instance of $Q_{\mathrm{R}}$ begins within the following detected critical windowthat is, within $\left[t+d_{1}, t+d_{2}\right]$. Such instances of $Q_{\mathrm{L}}$ and $Q_{\mathrm{R}}$ are, therefore, connected to form an instance of the new larger pattern, $Q$, which begins where the $Q_{\mathrm{L}}$ instance begins and ends where the $Q_{\mathrm{R}}$ instance ends. The double series of $Q$ is thus determined.

Therefore, if $Q_{\mathrm{L}}=X_{1} \ldots X_{m}$ and $Q_{\mathrm{R}}=Y_{1} \ldots Y_{n}$, then $Q=X_{1} \ldots X_{m}\left[d_{1}, d_{2}\right] Y_{1} \ldots Y_{n}=Z_{1} \ldots Z_{m+n}$ (see Figure 4). The new pattern thus inherits all the behavioral terms of $Q_{\mathrm{L}}$ and $Q_{\mathrm{R}}$ and their temporal structure. Only a (possibly very small) subset of the instances of either $Q_{\mathrm{L}}$ or $Q_{\mathrm{R}}$ may be involved - that is, $Q_{\mathrm{L}}$ and/or $Q_{\mathrm{R}}$ may occur much more often than $Q$. The detection of the critical interval relating the simple series in Figure 4 is described in Appendix C.

Patterns with double series (line section series) identical to already detected patterns are treated in a special way, as will now be explained. 


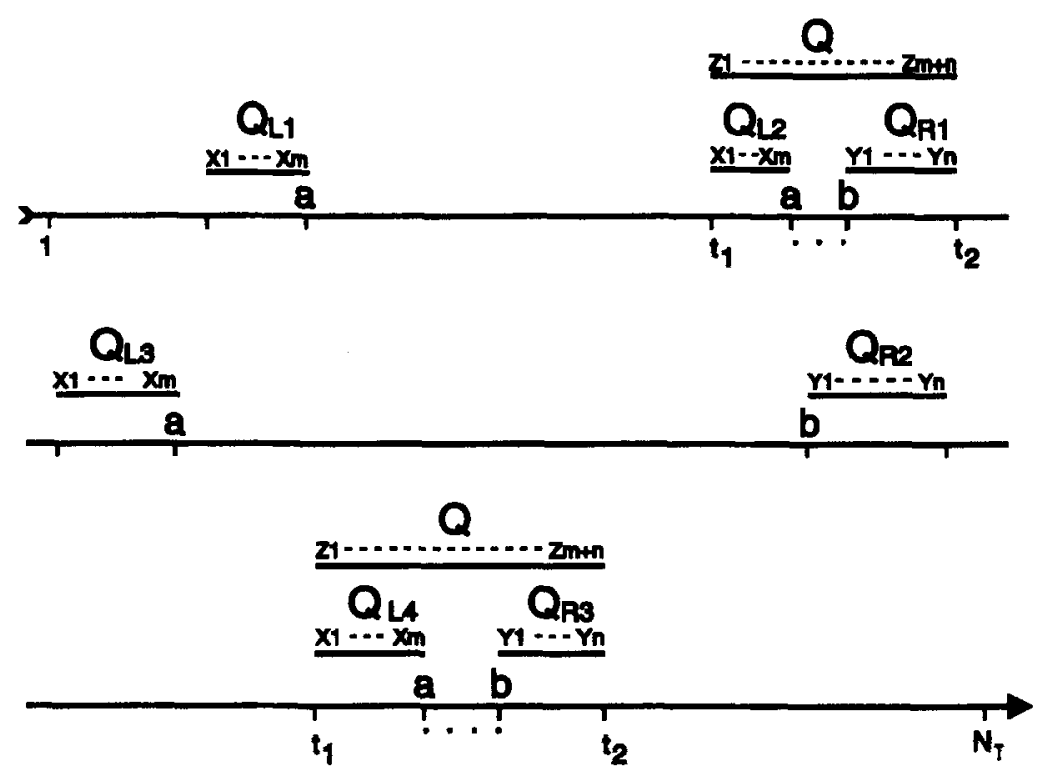

Figure 4. This figure shows $N_{Q \mathrm{~L}}=4$ occurrences of a pattern $Q_{\mathrm{L}}=X_{1} \ldots X_{m}$, and $N_{Q R}=3$ occurrences of pattern $Q_{R}=Y_{1} \ldots Y_{n}$ within observation period $\left[1, N_{T}\right]$. The location and duration of pattern instances are also indicated with line segments. The two critically related simple series $\left(Q_{\mathrm{L} .2}\right.$ and $Q_{\mathrm{R} .1}$, see the text) are indicated with as and $b s$, respectively. The two pairs of values $\left(t_{1}, t_{2}\right)$ are the double series of the resulting pattern $Q=\left(Q_{\mathrm{L}} Q_{\mathrm{R}}\right)=X_{1} \ldots X_{m} Y_{1} \ldots Y_{n}=Z_{1} \ldots Z_{m+n}$.

\section{Redundant Detection}

\section{and Identical Double Series}

More than one binary tree of $\mathrm{CI}$ relations may correspond to the same underlying T-pattern, which may, thus, be completely detected as different T-patterns, all with identical double series but different trees. For example, ((A B) (C D)) and (A ((B C) D)). Moreover, various incomplete versions (i.e., those with missing parts) of the same complete pattern may also be detected, and if their beginnings and endings are identical to the complete pattern, they will also have the same double series-for example, (A (C D)) and ((A B) D). The double series of a pattern completely determines which $\mathrm{CI}$ relationships it will form; so, for patterns with identical double series, the first one detected may represent all those detected later. On the other hand, a pattern like ( $\mathrm{A}(\mathrm{BC})$ ), with a different double series, might grow into a pattern more complete than ((A B) (C D))-for example, ((A (B C)) (R D)). This can only be known after Stage 1.

Therefore, if the double series of the new pattern is not identical to that of any already detected pattern, it is added to the data and considered as a potential $Q_{\mathrm{L}}$ or $Q_{\mathrm{R}}$ part of still longer patterns. Otherwise, it is stored away until the competition for completeness begins.

\section{Stage 2: Completeness Competition}

This last stage deals with the elimination of detected patterns that are partial or redundant versions of other detected patterns. Pattern $Q_{x}$ is thus considered less complete than Pattern $Q_{y}$ if $Q_{x}$ and $Q_{v}$ occur equally often and all events that occur in $Q_{x}$ also occur in $Q_{y}$. If the reverse is also true, $Q_{x}$ and $Q_{y}$ are considered equivalent, and one is arbitrarily selected, and the other dropped. Thus, the more or less arbitrary binary tree structure imposed for detection purposes is disregarded, making indifferent the order in which series pairs are considered during the search.

\section{Adjusting Search Parameters}

When searching for T-patterns with the Theme program, some search parameters can be adjusted. The principal ones are $\alpha$, the significance level used by the critical interval tests, and $N_{\min }$, the minimum number of times a pattern must occur. Although patterns occurring at least twice may, in principle, be detected, any higher minimum number can used and is a powerful way to reduce the number of detected patterns. The choice of $\alpha$ is not automatic, but the default value .005 often works quite well. However, the rule of thumb is to do repeated analysis, starting with a very low value, such as .00001 , at which no patterns or only very few and short patterns are detected. When the value is gradually increased, longer patterns start to appear. But when a certain approximate level has been reached, most of the longest and most interesting patterns have appeared, and increasing the $\alpha$ value leads to a decreasing difference in number and complexity of patterns, as compared with an analysis of the same data after their randomization (see the next section). Deciding which $\alpha$ value to use is, thus, somewhat like adjusting a microscope's amplification level. 


\section{Patterns Formed by Chance}

In fairly large data sets, the use of a null hypothesis means that some T-patterns are expected to occur by chance, even in randomized data. Therefore, detecting some T-patterns in such data is not an error. But this calls for an evaluation of the validity of the results, and three approaches are proposed. The first is external validation, which considers how well the detected patterns correspond to prior knowledge about the behavior. The second, purely statistical approach is to compare the results with those obtained by using the same search parameters after the data have been randomized. To randomize data, the Theme program replaces each occurrence series in the original data with a series containing the same number of random time points within the same observation interval, $\left[1, N_{T}\right]$. This can be done repeatedly, analyzing the randomized data with the same search parameters as those used when analyzing the initial (nonrandomized) data. A search for T-patterns is considered successful when considerably more and/or longer T-patterns are found in the original data than in any of its randomized versions. How much difference is required may depend on various factors, such as external validation and the type of research. By specifying very strict search parameter values, it is usually possible to exclude practically all detection in randomized data, but this may hinder the detection of interesting patterns in the original data, which might be validated in other ways.

The third kind of validation is graphical, since looking at the pattern diagrams can provide important information about the detected regularity (see Figures 7, 8, and 9).

\section{DERIVED TERMS}

\section{Transition Probabilities}

For each critical interval, there are two transition probabilities (relative frequencies), $N_{\mathrm{AB}} / N_{\mathrm{A}}$ and $N_{\mathrm{AB}} / N_{\mathrm{B}}$ that is, respectively, the forward conditional probability that, given an occurrence of $\mathrm{A}$ at $t$, it is followed by an instance of $B$ within the critical interval $\left[t+d_{1}, t+d_{2}\right]$, and the backward conditional probability that, given $\mathrm{B}$ at $t$, an instance of A occurs within $\left[t-d_{1}, t-d_{2}\right]$ (where $N_{\mathrm{A}}, N_{\mathrm{B}}$, and $N_{\mathrm{AB}}$ are the number of occurrences of Patterns $\mathrm{A}, \mathrm{B}$, and $\mathrm{AB}$, respectively). Either one or both of these forward and backward transition probabilities can be near zero (see the CI test in Appendix A), which underlines the importance of time - that is, the $\mathrm{CI}$ relationin T-patterns. The Theme program calculates these conditional probabilities, as well as the conditional probability of a T-pattern occurrence, given an occurrence of any one of its event types.

\section{Markers}

If the probability that a particular pattern, $Q$, is occurring is higher than some preset value $(k)$, given an occurrence of a particular event type $E$ that is a component of $Q$-that is, if $\left(N_{Q} / N_{E}\right)>k$-then $E$ is called a $(k)$ marker for $Q$ (Magnusson \& Beaudichon, 1997).

\section{CHILDREN'S DYADIC OBJECT PLAY: AN EXAMPLE STUDY}

This study concerns an interaction between two 5year-old girls playing together with one toy for as long as they wanted (i.e., here, for $13 \mathrm{~min}$ and $52 \mathrm{sec}$ ). An existing list of (ethological) categories of children's behavior (McGrew, 1972), with minor modifications, was used for the coding (see Appendix D) on the basis of the implicit assumption that these behaviors were relevant in this situation. The only explicit hypothesis was that complex behavior and interactions at least sometimes involve hidden T-patterns that can be detected with the proposed algorithm. No hypotheses were formulated regarding any particular pattern that might be found.

\section{Setting}

The observation setting was a large room $(5 \times 6 \mathrm{~m})$ split into two equal halves with a thin $1.5-\mathrm{m}$-high partition. It had an approximately 2 -meter-long section made of transparent plastic that did not quite reach the floor, leaving a 15-cm-high opening, through which the children could exchange the toy, a hand-held picture viewer with a few picture cards (called pictcard below). The children were brought into the room, one on each side of the partition, and one child was given the viewer and the picture cards. The children were told they could play with the viewer as long as they wanted.

\section{Video Recording}

The video recording started as one of the children began manipulating the viewer and ended when the children spontaneously stopped playing and left the room. Two video cameras were used, each hidden about $2.5 \mathrm{~m}$ from each side of the transparent wall section behind and slightly above one child and facing the other. Each camera thus provided a frontal view of one child (and a view from behind of the other). The image from each camera was recorded on one side of the video screen, using a splitscreen technique. The video recording was then digitized at 15 frames per second, which was also the time resolution used for coding and was more than was needed to separate all the occurrences of the most frequent event type.

\section{Coding}

Three categories were specially defined, since they seemed particularly relevant for the situation-that is, "have-viewer," "view," and, the only verbal behavior category, "order,viewer." Others have been qualified by their focus, such as "glance-at,partner" and "look-at,viewer" (see Appendix D).

\section{Categories Versus Event Types}

For each child, here called $\mathrm{X}$ and $\mathrm{Y}$, both beginnings (B) and endings (E) were coded for most of the categories, so the event types used in coding are, for example, $X, B, L O O K-A T, V I E W E R$, meaning $X$ begins to look at 


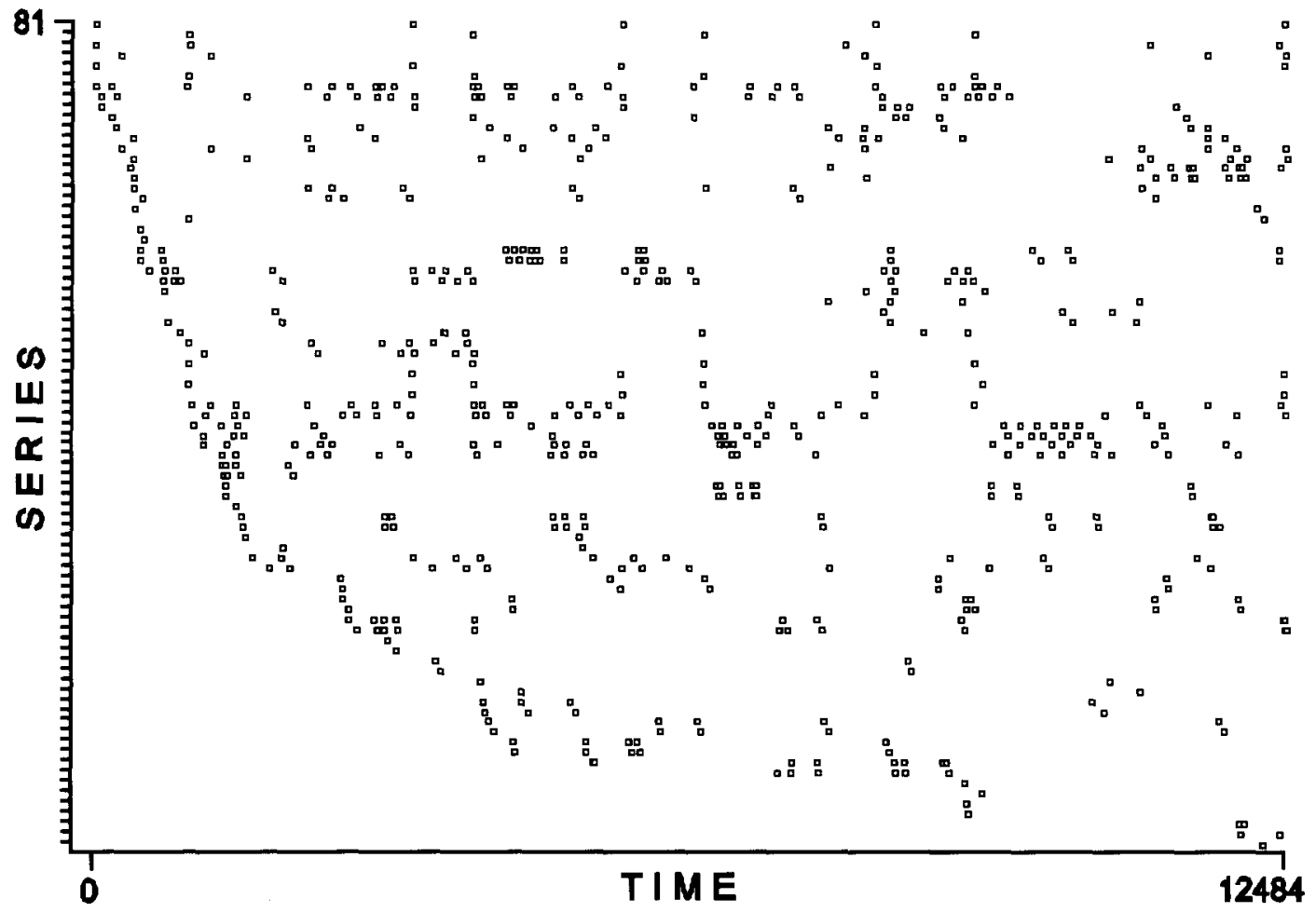

Figure 5. This figure shows a behavior record of the type described in the text. It consists of 81 series of occurrence times ( 1 for each coded event type) arbitrarily ordered according to their first occurrence time. The behavior was coded from a digitized video recording of approximately 13:52 min of continuous object play between two 5-year-old children (see the text). Time is in 1/15 sec (i.e., in digital video frames).

the viewer, and Y,E,LOOK-AT,VIEWER, meaning Y ends looking at viewer (see Appendix D). Consequently, the number of event types is much greater than the number of categories, and each event type has its own occurrence times series, whereas the same category may be involved in a number of event types. The coding here resulted in the set of event type occurrence series (behavior record) shown in Figure 5.

\section{Pattern Diagrams for Longer Patterns}

When many types of events are involved, the type of presentation in Figure 1 is replaced by the kind of diagram shown in Figures 7 and 9 (see below). These are more closely related to that of Figure 5 , in that they show, in a similar format, all those series from the behavior record that are involved in the pattern.

To facilitate the reading of the pattern diagrams below, Figure 6 shows the correspondence between the two types of diagrams (Figure 1 vs. Figure 9). Regarding diagram types, Figure 7 corresponds to the two middle boxes of Figure 6, whereas Figure 9 corresponds to its two lower parts. The top box of Figure 8 is a horizontally stretched copy (longer time axis) of the right box in Figure 7, while its bottom box is like those of Figures 6 and 9. (Diagrams like those in Figures 5, 7, 8, and 9 are automatically produced by Theme; see below.)

\section{RESULTS}

After a few search parameter values had been tried, the T-pattern shown in Figures 7 and 8, described below, was detected with $\alpha=.005$ and $N_{\min }=4$, using the free $\mathrm{CI}$ algorithm (see Appendix C).

With these parameters, 341 different patterns of varying length and content were found, the longest one being of length $m=25$ (the number of event types involved). It, moreover, corresponded with prior knowledge, since it corresponded perfectly with play and exchange of a toy between two children, which is what the whole situation was about.

Randomization and analysis with the same search parameter values repeated 50 times produced, at best, patterns that were about 3 times fewer and 3 times shorterthat is, 40-120 different nonsense patterns of maximum length varying from 5 to 8 . The fact that some of the event types in the real data were logically connected may play some role in this big difference, but these were too few to account for much of the difference. In any case, the strong external validation and the regularity seen in the pattern diagram make remote the possibility of the pattern's being produced by pure chance.

The many different patterns detected in the real data provided complementary insights, but the one shown in 


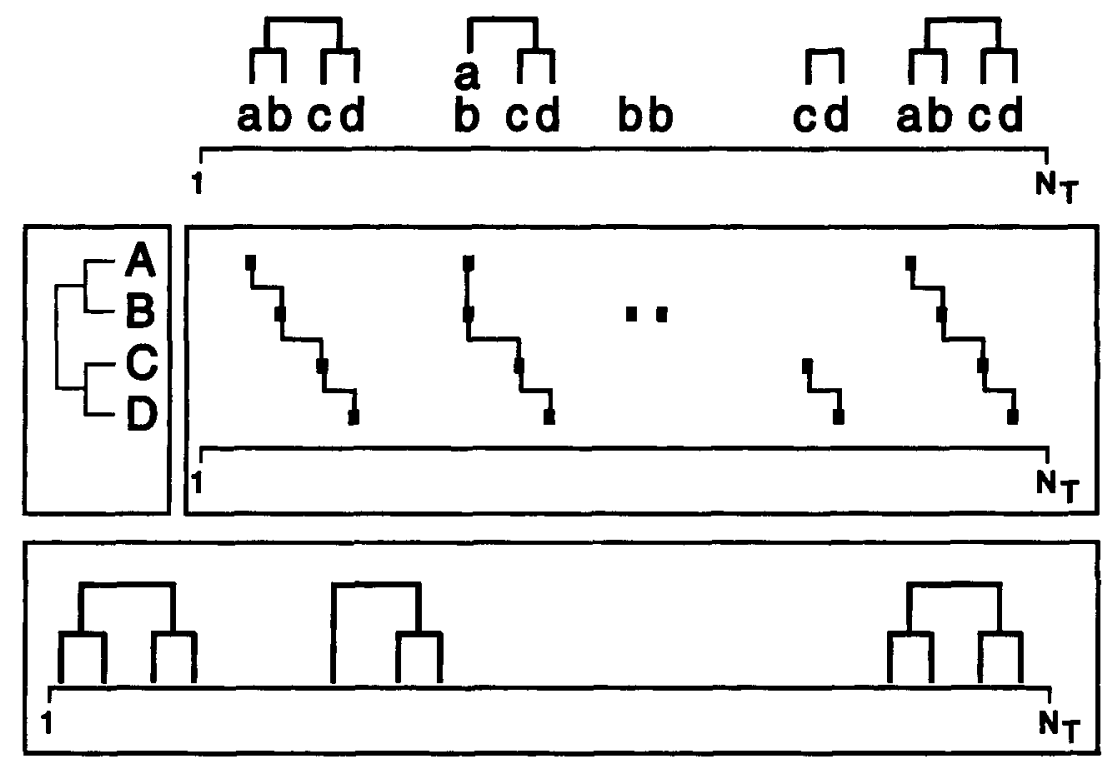

Figure 6. This figure has three main parts, each involving the same $\left[1, N_{T}\right]$ observation period. The uppermost part (see the text and Figure 1) and the middle part (two boxes) contain the same information. The middle-left box shows the hierarchical construction of the pattern, whereas the middle-right box shows the occurrence time points of each of its event types and the connection of points to form pattern occurrences. In the uppermost part, concurrent events appear on top of each other, whereas in the right and bottom boxes, their connection branch becomes a simple line whereby the binary tree becomes partly invisible. The bottom box is like the uppermost part, but with no letters and with only complete pattern instances showing.

Figure 7 (and Figure 8) was the longest, and it gives both a global and a reasonably detailed view of the interaction. Note, however, that this particular pattern occurs cyclically and that each new occurrence even begins where the last one ends (about the possibility of discovering cyclical organization in data by first detecting T-patterns, see Magnusson, 1989). Most T-patterns are shorter, occur more often, and, with irregular distances between instances, cover a much smaller percentage of the observation period, as is, for example, the case with some of the subpatterns in Figures 7 and 9.

The pattern shown in Figure 7 (and Figure 8) starts right at the beginning of the interaction, and its four occurrences cover, continuously, nearly $100 \%$ of the observation time. It is repeated four times, with very similar time distances between its parts each time. Some of the relations are logical necessities, so they should appear together in the pattern, and they do. Referring to the numbers in the top left box, this process or pattern may be expressed in words in, for example, the following way. (1) Y gets the viewer to her side of the screen and, then, (2) stops looking at it and instead (3) starts looking into the viewer. (4-8) $\mathrm{X}$ then begins a series of automanipulations. Then $(9-10), \mathrm{Y}$ loses the viewer, and $X$ gets it and (11) immediately begins manipulating it. (12-15) $\mathrm{X}$ then twice views the pictures in the viewer for more than $3 \mathrm{sec} .(16-18) \mathrm{Y}$ ends being immobile and begins and ends looking at her partner. (19-20) $Y$ then begins and ends looking at a picture card and then (21-22) begins and ends automanipulation. (23-24) $\mathrm{X}$ then stops having and manipulating the viewer. (25) $Y$ gets the viewer again.

Once this long pattern had been performed, it was immediately repeated in full-three times. Note that the last pattern occurrence-that is, just before the children stopped playing-lasted longer (was performed more slowly) than the others.

\section{Head Tilts, Immobility, Glances, and Commands}

The pattern shown in Figure 9 was detected in the same data but captured a somewhat different aspect of the organization of this interaction. New behaviors were involved - that is, "order, viewer," and "headtilt"- but initially, no verbal acts were included in the coding of this interaction. Then category "order, viewer" (see Appendix D) was added, to see whether it would turn up in any patterns. As may be seen in Figure 9, it did. Moreover, it fell almost right into the longest pattern (Figure 7), which, however, tells the same general story about the interaction, but without it. This suggests the possible danger of taking a narrow look at the structure of such interactions, which easily happens if, for example, only "order,viewer" and "have-viewer" had been coded, thus ignoring the larger scheme, where such highly different behaviors as "automanipulate," "order,viewer," "immobile," "view,long," "glanceat,partner," and "headtilt" (see Appendix D) all occur again and again (four times) at nearly exactly the 


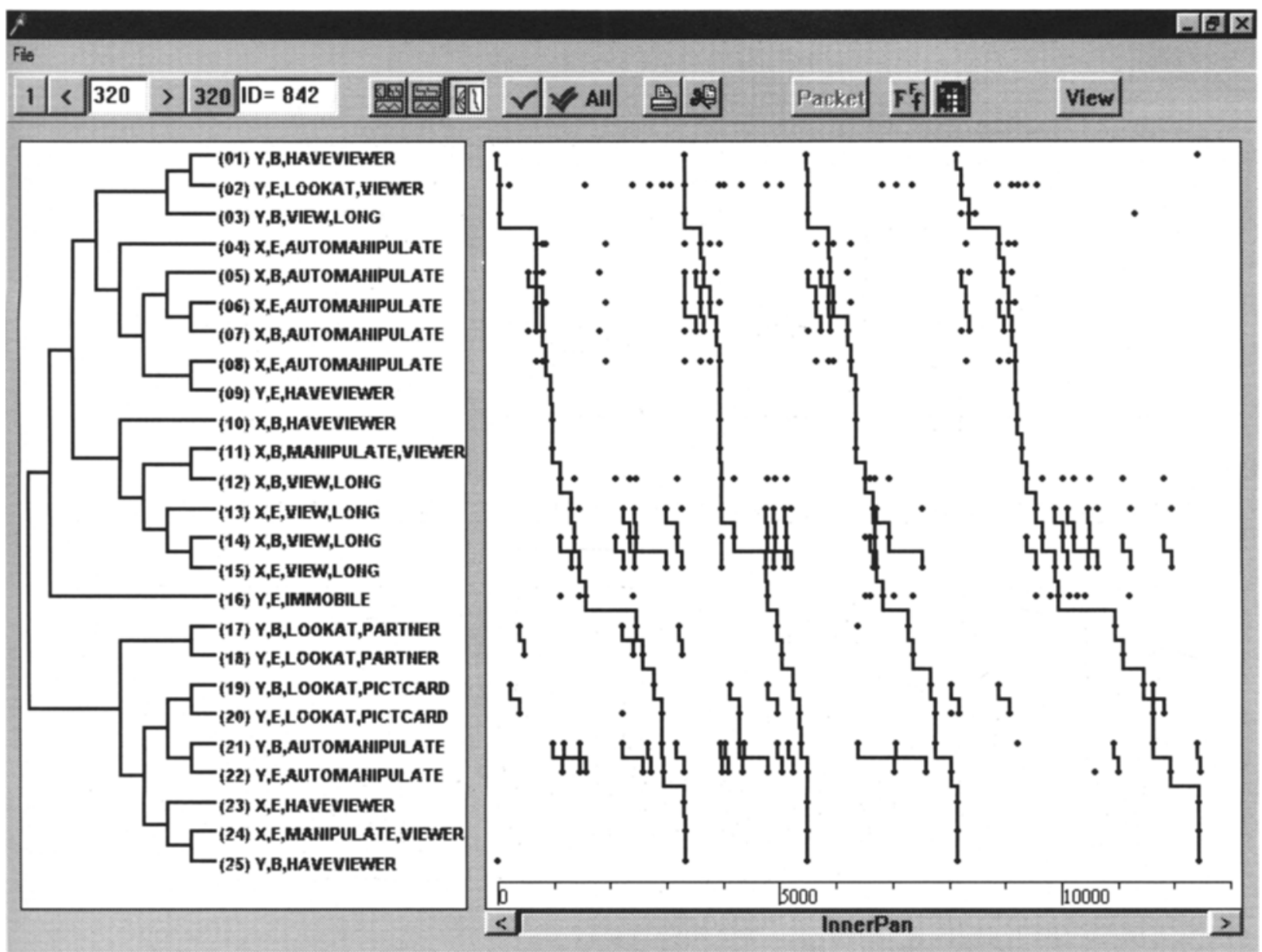

Figure 7. Optimized for the readability of the many event type names, this figure shows a T-pattern composed of 25 event types, numbered 1 to 25, gradually detected by the bottom-up, level-by-level (breadth-first) algorithm of the Theme program. For each event type in the left box, its occurrence series, as in the behavior record, appears immediately to its right in the right box. The first connected event types (left box)-that is, those at Level One-are (right box occurrences of) event types (1 and 2), (6 and 7), (8 and 9), (11 and 12), (14 and 15), and so forth. At Level Two, they are ((1 and 2$)$ and 3$),(5$ (6 and 7$)),(13$ and (14 and 15)), and so forth. Time distances involved at each $\mathrm{CI}$ connection appear in the horizontal part of point connections, which appear, for example, clearly at the last (7th) level, where subpattern $(1 \ldots 16)$ is connected to subpattern $(17 \ldots 25)$. See also the caption to Figure 6.

same temporal positions relative to each other. One could get the impression that "order, viewer" is simply the cause of the following "b, have-viewer," whereas any effect of "order,viewer" may depend on its timing relative to various other components of the pattern.

\section{DISCUSSION}

\section{Perceiving the Detected Patterns}

Observers who watched the video record very carefully in normal and slow motion overlooked the pattern shown in Figure 7, and its regularity and much of its behavioral content, as well as its coverage of nearly $100 \%$ of the observation time, came as a complete surprise. Even after it has been detected, following it through a 13:52-min video recording requires intense concentration and is hardly possible without much practicing. Theme allows finding and playing the video sections corresponding to each occurrence of a detected pattern. But when so many other things are happening (see Figure 1), for so long and at so many different temporal scales at the same time, this may not be enough to "see" a pattern even when it has been pointed out.

Although the patterns presented above are mostly nonverbal, structurally very similar patterns have been found in studies in which dyadic interactions were coded mostly in terms of verbal acts (Beaudichon \& Magnusson, 1999; Blanchet \& Magnusson, 1988; Magnusson \& Beaudichon, 1997). This suggests that T-patterns capture some important characteristics of the temporal organization of at least some behavioral streams, and in a way that is both in accordance with and complements previous knowledge. 

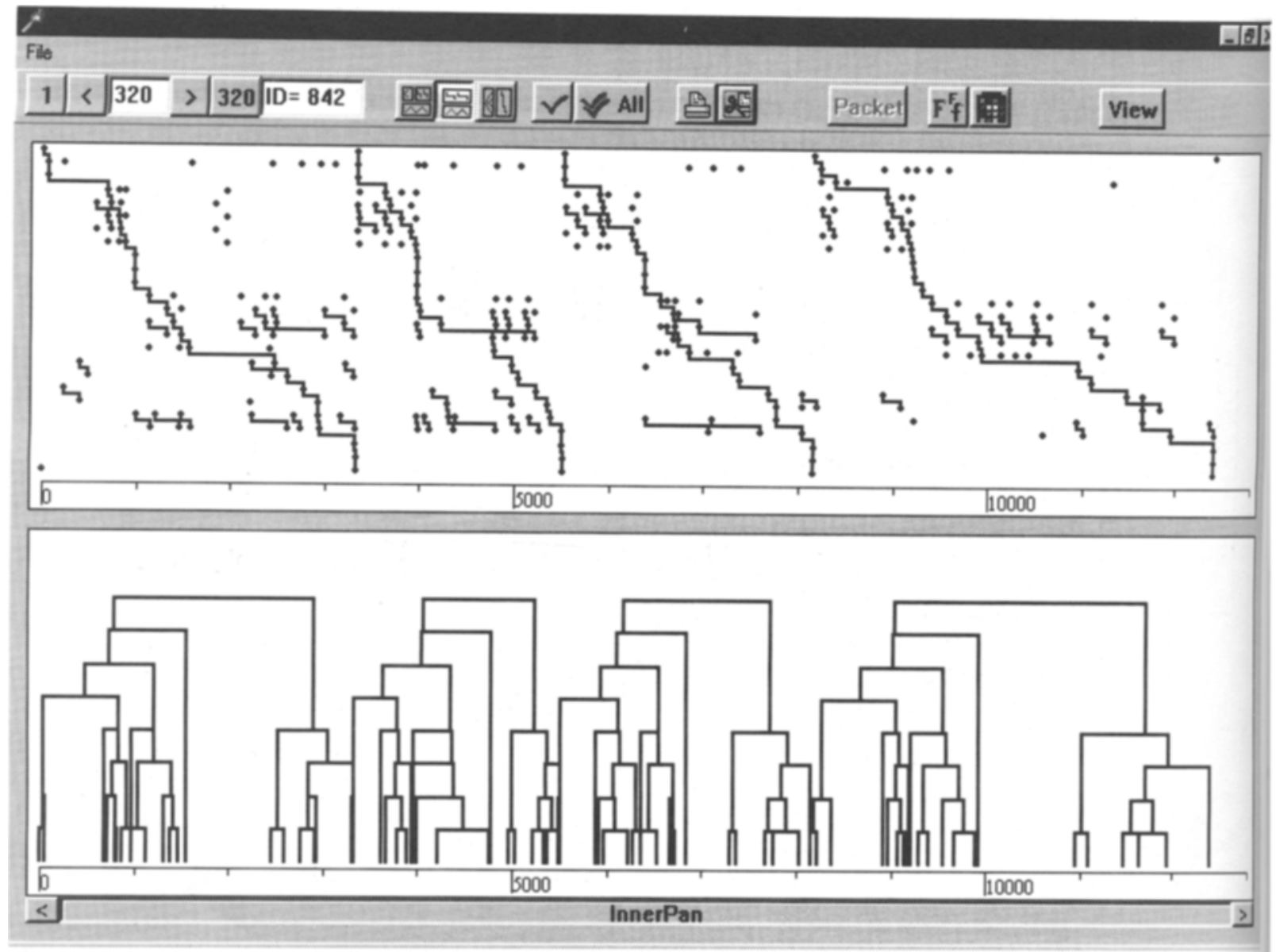

Figure 8. Optimized for easier reading of temporal information, this figure concerns the same pattern as that in Figure 7, and the upper box of this figure is exactly that of Figure 7, except that time axis is drawn longer. The lower box diagram type is explained in the caption for Figure 6.

\section{Recurring Critical Intervals and Inverse Relations}

Figure 3 shows the simple series of Figure 4 and the occurrences of the detected CI. Notice that, whether empty or not, it has become an entity with its own time locations (occurrences). In the present T-pattern definition, the focus is on the nonempty cases. But what happens after empty ones - that is, when $B$ does not occur within the $\mathrm{CI}$ ? And especially when the $\mathrm{A} \rightarrow \mathrm{B}$ transition probability is high, as, for example, when a greeting that is usually returned is sometimes ignored? A definition and an algorithm are being prepared for this inverse relationship.

\section{What Do T-Patterns Mean?}

The question of what T-pattern mean has often been asked, and there is no single answer. It might be somewhat like asking, generally, What do phrases mean? Obviously, the answer would, at least, depend on the content of the phrase, how it is performed, and the general context. Some verbal phrases even have different meanings to different listeners and may also be hard to interpret or understand for most, which, again, is often true when the same word occurs within different phrases and general contexts.

\section{Why Do T-Patterns Happen?}

No single theory seems to predict or explain the emergence of T-patterns in behavior and interactions. Suggestions may, however, be found within the area of dynamic patterns and complexity studies (e.g., Holland, 1998; Kelso, 1997; Watt \& Vanlear, 1996), since key terms describing complex dynamic and self-organizing systems - that is, mechanism, agents, interaction, recurring patterns, and hierarchical organization (Holland, 1998, p. 9)-also surround the definition and detection of Tpatterns.

A particularly interesting case is the well known Game of Life, a cellular automaton invented by the Cambridge mathematician John Conway (see, e.g., a famous account by Gardner, 1970). In this game, a fairly high number of entities interact according to very few and simple rules. However, self-organization happens - that is, obvious complex repeated patterns emerge (and others may have been overlooked?). It is, thus, tempting to think of T-patterns as characteristic emergent phenomena in complex 


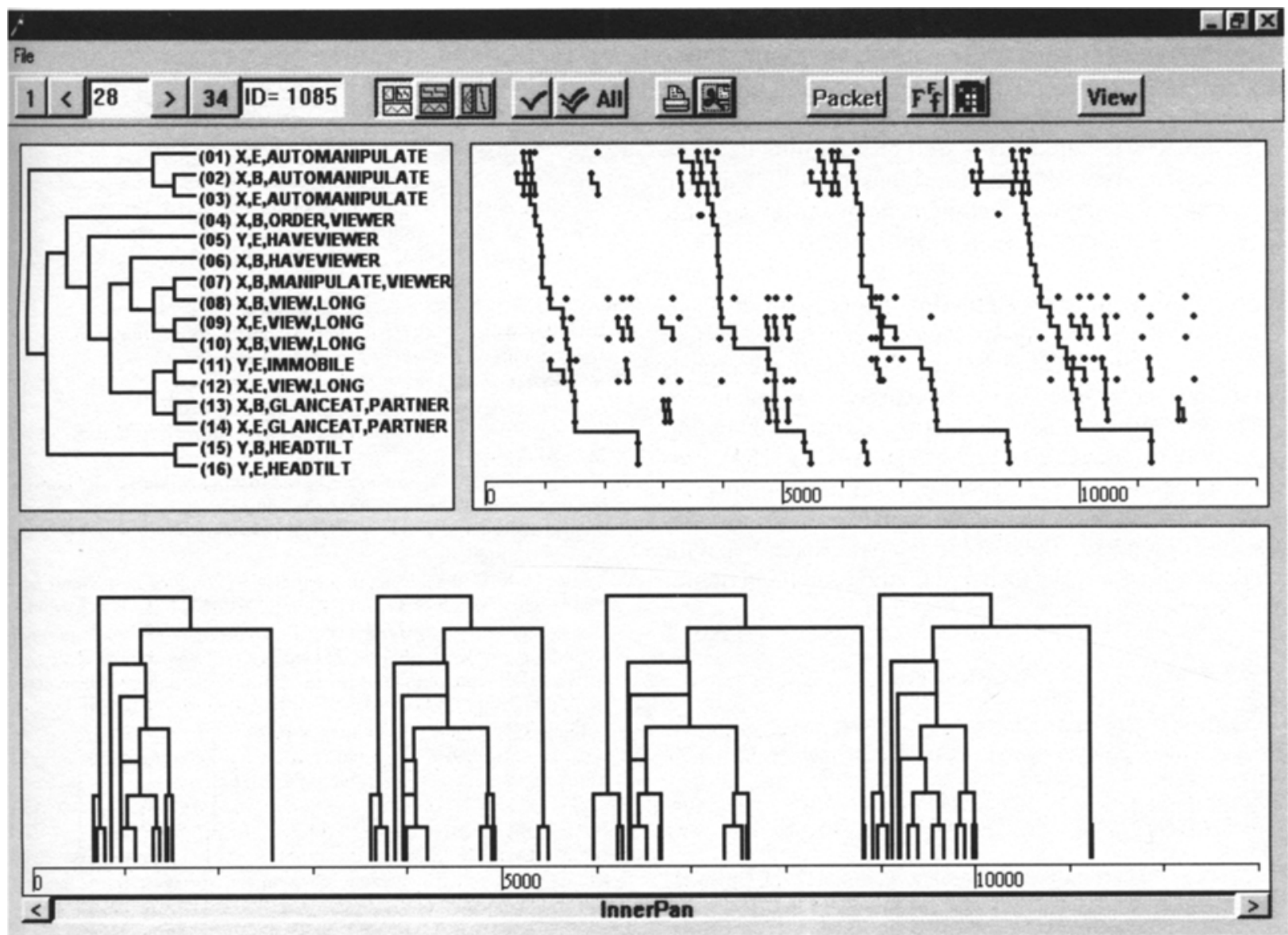

Figure 9. This figure describes a T-pattern including 16 event types. For the reading of this kind of diagram, see the caption for Figure 6, as well as for Figure 7 and the text.

dynamic systems involving one or more agents capable of a number of different behaviors and governed by interacting (sets of) rules (many or few, simple or complex). The T-patterns found in the dyadic interaction above might, thus, be seen as self-organization phenomena, under particular constraining conditions, emerging from the interaction of two populations of rules (or memes, more generally). (About heuristic rules that guide behavior, see, e.g., Todd \& Gigerenzer, 1999. About memes see, e.g., Blackmore, 1999.) In this view, it is only natural that novel patterns appear in every human interaction and make it unique.

\section{T-Associates and T-Packets}

The following derived definitions indicate the kind of conceptual development that the definition of pattern types such as the T-pattern may lead to.

Positive (or negative) associates of a T-pattern, $Q$, are T-patterns that are not components of $Q$ but occur significantly more (or less) often during a particular time zone, called Q's attraction/repulsion $(\mathrm{a} / \mathrm{r})$ zone. This zone may extend from somewhere before to somewhere after the occurrences of $Q$.

When a positive associate always occurs with $Q$ within its a/r zone, it is called a T-satellite of $Q$. A negative as- sociate of $Q$ that never occurs within $Q$ 's a $/ \mathrm{r}$ zone is called a $T$-taboo relative to $Q$. A T-pattern that has associates is, together with its associates and a/r zone, called a $T$ packet. A well-known example of a T-packet is, for example, the business dinner, where, apart form the normal dinner pattern, certain behaviors are especially likely and others especially unlikely to happen; some might even be satellites - for example, talking business-and there might be some taboos, too. (Definitions and detection algorithms, similar to those for CIs, are being tested.)

\section{Seeing Aid and Measurement Tool}

The principal aim of the Theme software has been to provide aid in discovering and understanding the structure of behavioral streams and, in that sense, to serve as a kind of seeing aid-a specialized structure or pattern scope (see Appendix E). But, for example, the number of different T-patterns detected in a behavioral stream or their average and/or maximum length may be used as measures of, for example, complexity or overall synchrony. Such measures may then be found to correlate with various external variables (see, e.g., Grammer et al., 1998). Theme has been used both as a structure scope and as a complexity measurement tool in a number of doctoral research pro- 
jects (Bensalah, 1992; Casagrande, 1995; Feron, 1992; Sevre-Rousseau, 1999; Sigurdsson, 2000; Tardif, 1996).

Theme is, moreover, being used in research on strategies in social interaction (Duncan, 1998), in sport research (Jonsson, 1998), and in research on relations between self-esteem and social interaction (Jonsson, 1997), as well as in research on animal feeding behavior (Martaresche, Le Fur, Magnusson, Faure, \& Picard, 1999).

\section{Pattern Concepts and Detection Tools Needed}

Finally, the following striking observation seems in place: "Only about $8 \%$ of all psychological research is based on any kind of observation. A fraction of that is programmatic research. And, a fraction of that is sequential in its thinking" (Bakeman \& Gottman, 1997, p. 184). Possibly, the still relatively limited offer of domain-specific methods and tools is a part of the explanation. In any case, it seems that useful types of hidden patterns in behavior need to be formally defined and methods adapted or created for their detection.

\section{REFERENCES}

Bakeman, R., \& GotTMAN, J. M. (1997). Observing interaction: An introduction to sequential analysis. Cambridge: Cambridge University Press.

Bakeman, R., \& QUERA, V. (1995). Analyzing interaction: Sequential analysis with SIDS and GSEQ. New York: Cambridge University Press.

Beaudichon, J., Legros, S., \& Magnusson, M. S. (1991). Organization des régulations inter et intrapersonnelles dans la transmission d'informations complexes organisées. Bulletin de Psychologie, 44, (Whole No. 399), 110-120.

Beaudichon, J., \& Magnusson, M. S. (1999). Children's problem solving and context: Role symmetry, task complexity and communication patterns. Manuscript submitted for publication.

BENSALAH, L. (1992), Effets de la relation amicale sur les comportements interactifs en situation dyadique de résolution de problemes. Unpublished doctoral thesis, Université Paris V-René Descartes, Sorbonne.

BlACKMORE, S. (1999). The meme machine. New York: Oxford University Press.

Blanchet, A., \& Magnusson, M. S. (1988). Processus cognitifs et programmation discursive dans l'entretien de recherche. Psychologie Française, 33, 91-98.

Casagrande, C. (1995). Organisation des interactions sociales dyadiques de nourissons de 4-5 mois: Contribution à une nouvelle méthode d'étude. Unpublished doctoral thesis, Université de FrancheComté, Besançon.

Chомsкy, N. (1959). Review of Skinner (1957). Language, 35, 26-58.

CHomsky, N. (1965). Aspects of the theory of syntax. Cambridge, MA: M.I.T. Press.

Colgan, P. W. (Ed.) (1978). Quantitative ethology. New York: Wiley. CosNiER, J. (1971). Clefs pour la psychologie. Paris: Seghers.

DAWKINS, R. (1976). Hierarchical organisation: A candidate principle for ethology. In P. P. Bateson \& R. A. Hinde (Eds.), Growing points in ethology (pp. 7-54). Cambridge: Cambridge University Press.

Dickins, D., Kwint, M. A. C . G., Magnusson, M. S., Neads, C. M., Noldus, L. P. J. J., \& Quera, V. (in press). OBSERVE: A multimedia course on the observational analysis of behavior. Behavior Research Methods, Instruments, \& Computers.

DunCAN, S. (1998, August). Analyzing individual differences in faceto-face interaction. Paper presented at 2 nd International Conference on Methods and Techniques in Behavioral Research, Groningen, The Netherlands. Abstract published at http://www.noldus.com

Duncan, S., \& Fiske. D. W. (1977). Face-to-face interaction: Research, methods and theory. Hillsdale NJ: Erlbaum.
EIBL-EIBESFELDT, I. (1970). Ethology: The biology of behavior. New York: Holt, Rinehart \& Winston.

Ekman, P., \& FrIESEN, W. V. (1978). Facial action coding system: A technique for the measurement of facial movement. Palo Alto, CA: Consulting Psychologists Press.

FERON, C. (1992). Les comportements socio-sexuels des souris staggerers males: Caracteristiques et effets de l'experience sociale. Unpublished doctoral thesis, Université de Paris XIII, Paris.

GARDNER, M. (1970, October). Mathematical games: The fantastic combinations of John Conway's new solitaire game, Life. Scientific American, pp. 120-123.

Grammer, K., Kruck, K. B., \& Magnusson, M. S. (1998). The courtship dance: Patterns of nonverbal synchronization in oppositesex encounters. Journal of Nonverbal Behavior, 22, 3-29.

Hayes-Roth, F., Waterman, D. A., \& Lenat, D. B. (Eds.) (1983). Building expert systems. London: Addison-Wesley.

Holland, J. H. (1998). Emergence: From chaos to order. Reading, MA: Addison-Wesley.

Jonsson, G. K. (1997). Self-esteem, friendship and verbal and nonverbal interaction [Abstract]. In A. Schmitt, K. Atzwanger, K. Grammer, \& K. Schafer (Ed.), New aspects of human ethology (p. 206). New York: Plenum.

JoNSSON, G. K. (1998). Detecting patterns in complex behavioral processes with The Observer and Theme. Abstract in L. P. J. J. Noldus (Ed.), Proceedings of Measuring Behavior '98: 2nd International Workshop on Methods and Techniques in Behavioral Research (p. 176). Wageningen: Noldus Information Technology. Abstract retrieved October 25, 1999 from the World-Wide Web: http:/www. noldus.webaxxs.net/events/index.html

Kelso, J. A. S. (1997). Dynamic patterns: The self-organization of brain and behavior. Cambridge, MA: MIT Press.

KöHLER, W. (1947). Gestalt psychology: An introduction to new concepts in modern psychology. New York: Liveright.

Lyon, M., Lyon, N., \& MaGnusson, M. S. (1994). The importance of temporal structure in analyzing schizophrenic behavior: Some theoretical and diagnostic implications. Schizophrenia Research, 13, 45-56.

Lyon, M., \& MAGNusson, M. S. (1982). Central stimulant drugs and the learning of abnormal behavioral sequences. In M. Y. Spiegelstein \& A. Levy (Ed.), Behavioral models and the analysis of drug action (pp. 135-153). Amsterdam: Elsevier.

MaGnusson, M. S. (1982, April). Temporal configuration analysis: Detection of an underlying meaningful structure through artificial categorization of a real-time behavioral stream. Paper presented at Workshop on Artificial Intelligence, University of Uppsala.

MAGnusson, M. S. (1983). Theme and syndrome: Two programs for behavior research. In D. Edwards \& A. Høskuldsson (Eds.), Proceedings of symposium in applied statistics (pp. 17-42). Copenhagen: NEUCC, RECKU \& RECAU.

Magnusson, M. S. (1988). Le temps et les patterns syntaxiques du comportement humain: Modèle, méthode et programme Thème. Revue des Conditions de Travail, 284-314.

MaGnusson, M. S. (1989). Structure syntaxique et rythmes comportementaux: Sur la détection de rythmes cachés. Sciences et Techniques de l'Animal du Laboratoire, 14, 143-147.

Magnusson, M. S. (1996). Hidden real-time patterns in intra- and interindividual behavior: Description and detection. European Journal of Psychological Assessment, 12, 112-123.

MAGNUSSON, M. S. (1998, August). Real-time pattern detection versus standard sequential and time series analysis. Paper presented at Measuring Behavior '98, 2nd International Conference on Methods and Techniques in Behavioral Research, Groningen, The Netherlands. Abstract retrieved October 25, 1999, from the World-Wide Web: http://www.noldus.webaxxs.net/events/index.html

Magnusson, M. S., \& Beaudichon, J. (1997). Détection de "marqueurs" dans la communication référentielle entre enfants. In J. Bernicot, J. CaronPargue, A. Trognon (Eds.), Conversation, interaction et fonctionnement cognitif (pp. 315-335). Nancy: Presse Universitaire de Nancy.

Martaresche, M., Le Fur, C., Magnusson, M. S., Faure, J. M., \& PICARD, M. (1999). Time patterns offeed pecking in chicks. Manuscript submitted for publication.

MCGREW, W. C. (1972). An ethological study of children's behavior. London: Academic Press. 
Monge, P. R., \& CAPPElla, J. N. (Eds.) (1980). Multivariate techniques in human communication research. New York: Academic Press.

Montagner, H. (1978). L'enfant et la communication. Paris: Stock/ Pernoud

Montagner, H., Magnusson, M. S., Casagrande, C., Restoin, A., Bel, J.-P., Hoang, P. N. M., Ruiz, V., Delcout, S., Gauffier, G., \& EPOULet, B. (1990). Une nouvelle méthode pour l'étude des organisateurs de comportement et systemes d'interaction du jeune enfant. Psychiatrie de l'Enfant, 33, 391-456.

NolDus, L. P. J. J. (1991). The Observer: A software system for the collection and analysis of observational data. Behavior Research Methods, Instruments, \& Computers, 23, 415-429.

Noldus, L. P. J. J., Trienes, R. J. H., Hendriksen, A. H. M., Jansen, H., \& JANSEN, R. G. (2000). The Observer Video-Pro: New software for the collection, management, and presentation of time-structured data from videotapes and digital media files. Behavior Research Methods, Instruments, \& Computers, 32, 197-206.

PIKE, K. L. (1960). Language: In relation to a unified theory of the structure of human behavior. Glendale, CA: Summer Institute of Linguistics.

SaCkETt, G. P. (Ed.) (1978). Observing behavior: Data collection and analysis methods (Vol. 2). Baltimore: University Park Press.

SCHERER, K. R., \& EKMAN, P. (EDS.) (1982). Handbook of methods in nonverbal behavior research. Cambridge: Cambridge University Press.

SchWAB, F. (1999, September). Smiling patterns in face to face inter- actions. Oral presentation at the 8th European Conference on Facial Expression: Measurement and Meaning, University of the Saarland, Saarbruecken, Germany. Abstract retrieved October 31, 1999 from the World-Wide Web: http://emotions.psychologie.uni-sb.de/facs/ abstract.htm

SEVRE-RousSEAU, S. (1999). Les competences sociales des enfants sourds-aveugles: Influences de l'interlocuteur et du contexte sur les échanges interpersonnels. Unpublished Doctoral thesis, Université Paris V-René Descartes, Sorbonne.

Sigurdsson, T. (2000). La relation de tutelle entre parents et enfants handicappés mentaux de 4 à 6 ans. Lille: Presses Universitaires du Septentrion.

SkinNer, B. F. (1957). Verbal behavior. New York: Appleton-CenturyCrofts.

SKINNER, B. F. (1969). Contingencies of reinforcement: A theoretical analysis. New York: Appleton-Century-Crofts.

TARDIF, C. (1996). Contribution à l'étude des interactions observées dans des études de dyades adultelenfant autiste. Unpublished doctoral thesis, Université Paris V-René Descartes, Sorbonne.

TINBERGEN, N. (1963). On the aims and methods of Ethology. Zeitschrift für Tierpsychologie, 20, 410-433.

TODD, P. M., \& GigERENZER, G. (1999). Simple heuristics that make us smart. New York: Oxford University Press.

WATT, J. A., \& VANLEAR, C. A. (Eds.) (1996). Dynamic patterns in communication processes. New York: Sage.

\section{APPENDIX A \\ The Critical Interval Test}

The $\mathrm{CI}$ test is based on the null hypothesis that $\mathrm{A}$ and $\mathrm{B}$ are independently and purely randomly (Poisson) distributed over the observation period $\left[1, N_{T}\right]$, with a constant probability of B's occurring within the basic time unit of $P(\mathrm{~B})=N_{\mathrm{B}} / N_{T}$ and, thus, of not occurring of $P(\sim \mathrm{B})=1-P(\mathrm{~B})$. The probability of B's not occurring within any interval, $\left[d_{1}, d_{2}\right]$, of length $d=d_{2}$ $-d_{1}+1$, is therefore, $\mathrm{P}(\sim \mathrm{B})^{d}$, and the probability of one or more occurrences of $B$ (i.e., of at least one occurrence of $B$ ) within an interval of that length is $1-\mathrm{P}(\sim \mathrm{B})^{d}$.

The statistically expected number of the $N_{\mathrm{A}}$ intervals following the $N_{\mathrm{A}}$ occurrences of $\mathrm{A}$ that contain one or more occurrences of $\mathrm{B}$ is thus $N_{\mathrm{A}} *\left[1-P(\sim \mathrm{B})^{d}\right]$. (To simplify, the possible overlapping of intervals is not taken into account.)

The a priori probability $p=P\left(\geq N_{\mathrm{AB}}\right)$ of $N_{\mathrm{AB}}$ or more of the $N_{\mathrm{A}}$ intervals containing one or more occurrences of $\mathrm{B}$ is thus $1-$ $P\left(<N_{\mathrm{AB}}\right)$. This $p$ value is the probability that $N_{\mathrm{AB}}$ or more cases of A occurring at $t$ will be followed by B within $\left[t+d_{1}, t+d_{2}\right]$. Thus, it is calculated by using the binomial distribution with $N_{\mathrm{A}}$ as the number of trials and $1-P(\sim \mathrm{B})^{d}$ as the probability of success (i.e., of one or more occurrences of B within each of the $N_{\mathrm{A}}$ intervals of length $d$ ). This probability is, thus, one minus the sum of the probabilities of all possible lower values of $N_{\mathrm{AB}}$-that is, all values from 0 to $N_{\mathrm{AB}}-1$. That is, $p=P\left(\geq N_{\mathrm{AB}}\right)=1-\sum$ binomial $\left(N_{\mathrm{A}}, i, 1-\mathrm{P}(\sim \mathrm{B})^{d}\right) ; i=0 \ldots N_{\mathrm{AB}}-1$. Consequently, $p$ is compared with the specified significance level.

Note that $p$ is a function of $N_{T}, N_{\mathrm{A}}, N_{\mathrm{B}}, d=d_{2}-d_{1}+1$, and $N_{\mathrm{AB}}$ but that, for a given pair of series $\mathrm{A}$ and $\mathrm{B}$ within a given observation period, only $d$ and $N_{\mathrm{AB}}$ can vary and that $p$ increases with $d$ and decreases with $N_{\mathrm{AB}}$. So, if $d$ (the CI size) is sufficiently small, the value of $p$ may be significant, even if $N_{\mathrm{AB}}$ is very small relative to either $N_{\mathrm{A}}$ or $N_{\mathrm{B}}$. Inversely, if the $\mathrm{CI}$ is large ( $Q_{\mathrm{L}}$ to $Q_{\mathrm{R}}$ distances vary significantly), $p$ may not be significant for any $N_{\mathrm{AB}}$ value.

(When conditions allow, the Poisson and normal approximations, respectively, to the binomial distribution are used to avoid extreme values and consequent value overflow in the computer.)

\section{APPENDIX B \\ Examples of Critical Interval Testing}

This section refers to the four minimal behavior records in Figure 2 . Since the only possible $(\mathrm{AB})$ patterns are obvious, a search algorithm (see Appendix $C$ ) is not involved, but the use of the $\mathrm{CI}$ test (see Appendix A) is illustrated (calculations may contain slight rounding errors). The following calculations assume that $N_{T}=100$.

Common to all four cases is that A and B occur only twice each, and the probabilities of $\mathrm{B}$ occurring and not occurring, are thus, respectively, $P(\mathrm{~B})=N_{\mathrm{B}} / N_{T}=2 / 100=.02$ and $P(\sim \mathrm{B})=1$ $-P(\mathrm{~B})=1-.02=.98$.

\section{Case 1}

Here, $\mathrm{A}$ is followed by $\mathrm{B}$ only once, so no Cl relationship can be calculated.

\section{Case 2}

Here $A$ occurs at 5 and at 40 , whereas B occurs at 20 and 95 . The distances from each $\mathrm{A}$ to the closest following or concurrent $\mathrm{B}$ are, thus, 15 and 55 , respectively. The only possible $\mathrm{CI}$ is therefore $[15,55]$ and its length is $d=[(55-15)+1]=41$. This means that there is a window of length $d=41$ following occur- 


\section{APPENDIX B (Continued)}

rences of $A$ that twice contains at least one instance of $B$ (i.e., $N_{\text {AB }}=2$ ). The a priori probability of this observation is calculated, using the CI test described in Appendix A. Therefore, $p=$ $1-\sum \operatorname{binomial}\left(2, i, 1-.98^{41}\right)=1-(.191+.492)=.32$ (where $i=0 \ldots N_{\mathrm{AB}}-1$ ), which is not significant--that is, a CI or a T-pattern is not found.

\section{Case 3}

Here A occurs at 6 and at 80 , whereas B occurs at 19 and 95 . The distances from $A$ to the first following $B$ are, thus, 14 and 16 , respectively. The only free CI possible is thus $[14,16]$ of length $d=3$. Therefore, $p=1-\sum \operatorname{binomial}\left(2, i, .98^{3}\right)=1-(.887+$ $.109)=.003$ (where $\left.i=0 \ldots N_{\mathrm{AB}}-1\right)$, which is highly significant, so that, per definition, a free T-pattern (AB) is found.
To test whether the conditions for a fast pattern are fulfilled, the same calculation must be carried out for the interval $[0,16]$ of length $d=17$. The result is $p=.08$, which is not significant at the .05 level.

\section{Case 4}

Here, A occurs at 10 and at 80 , and $B$ at 13 and 82 . The distances from $A$ to the first following $B$ are, thus, 3 and 2, respectively. There are two CI possibilities, the free $[2,3]$, with $d=2$, and the fast $[0,3]$, with $d=4$.

In the free case, $p=1-\sum \operatorname{binomial}\left(2, i, 1-.98^{2}\right)=1-$ $(.922+.076)=.002$, so a free T-pattern is found.

In the fast case, $p=1-\sum \operatorname{binomial}\left(2, i, 1-.98^{4}\right)=1-$ $(.850+.144)=.006$, so a fast $\mathrm{T}$-pattern is also found.

\section{APPENDIX C \\ The Critical Interval Search Algorithim}

This section describes simple, easily programmed algorithms for the detection of fast and free critical intervals $\left[d_{1}, d_{2}\right]$ that both use the $\mathrm{CI}$ test described in Appendix A. Both versions begin by establishing a particular kind of table of distances measured from each occurrence of $A$ to the first following or concurrent occurrence of $\mathrm{B}$. Here, used as an example, Table $\mathrm{Cl}$ refers to the simple series in Figures 3 and 4, with $N_{T}$ set to 300 . Then, a frequency table, Table $\mathrm{C} 2$, of the distances in Table $\mathrm{Cl}$ is generated and sorted by distance lengths. Note that, when more than one occurrence of $A$ is followed by the same occurrence of $B$, it is not included in Table C2 (see the Bursts and Overlapping Intervals section, below).

Both algorithms place a window (a potential $\mathrm{CI},\left[d_{1}, d_{2}\right]$ ) on the frequency table, which first covers the whole table - that is, all its rows and distances. This window is then tested and resized, if needed, until either a CI is found or the table's data are exhausted. The fast CI algorithm only modifies $d_{2}$, since $d_{1}=0$, per definition. $N_{\mathrm{AB}}$ in each CI test is the sum of column $N$ (Table C2) over the frequency table rows where $d_{1} \leq t_{\mathrm{B}}-t_{\mathrm{A}} \leq d_{2}$.

\section{Fast Critical Interval Search}

The fast $\mathrm{CI}$ algorithm begins by fixing $d_{1}=0$ (by definition) and setting $d_{2}$ equal to the longest (and last) distance in the frequency table - that is, for Table $\mathrm{C} 2$, first $d_{2}=74$. It then calculates the $p$ value for $\left[0, d_{2}\right]$. If $p$ is not significant, $d_{2}$ is reduced to the next lower value in the table, and $p$ for $\left[0, d_{2}\right]$ is calculated again. This continues until either a significant $p$ value is obtained (a $\mathrm{CI}$ is found; here, $[0,8]$ ) or no more distance values are left (a $\mathrm{Cl}$ is not found). The corresponding $\mathrm{A}$ and $\mathrm{B}$ occurrences, (T-pattern AB occurrences) are found in those rows of Table Cl where $d_{1} \leq t_{\mathrm{B}}-t_{\mathrm{A}} \leq d_{2}$. See Figure 4 .

\section{Free Critical Interval Search}

The search algorithm for a free CI may adjust both $d_{1}$ and $d_{2}$. First $d_{1}$ is set to the shortest (first) distance in the frequency table (Table C2), and $d_{2}$ to the longest (last) distance in the search table (i.e., $[5,74]$ in Table C1), and then its $p$ value is calculated. As long as $p$ is not significant, two smaller windows are temporarily formed by, respectively, increasing $d_{1}$ to the next longer distance and decreasing $d_{2}$ to the next shorter distance. Their $p$ values are calculated, and the one with the lowest $p$ value becomes the current window. This process contin- ues until either $p$ becomes significant and a $\mathrm{CI}$ is found or the window size cannot be further reduced (a $\mathrm{CI}$ is not found). Here, $\mathrm{CI}=[5,8]$. See Figures 3 and 4 .

\section{Bursts and Overlapping Intervals}

In both algorithms, if more than one occurrence of $A$ has the same first following or concurrent $\mathrm{B}$, only the shortest one affects the value of $N_{\mathrm{AB}}$ in the CI test, whereas $N_{\mathrm{A}}$ and $N_{\mathrm{B}}$ are unaffected. This is an approximate but conservative way to deal with overlapping windows caused, for example, by bursts in A. Similarly, distances are measured from A only to the first following $\mathrm{B}$, and then the question of whether one or more $B \mathrm{~S}$ occur in a window (but not how many) is considered, which may be seen as an approximate way of dealing with possible bursts in B (since $N_{\mathrm{B}}$ remains unaffected whether B contains bursts or not). This, however, does not affect the result in the above example.

Table C1

Distances From A to B

\begin{tabular}{ccc}
\hline$t_{\mathrm{A}}$ & $t_{\mathrm{B}}$ & $t_{\mathrm{B}}-t_{\mathrm{A}}$ \\
\hline 28 & 84 & 56 \\
79 & 84 & 5 \\
115 & 189 & 74 \\
245 & 253 & 8 \\
\hline
\end{tabular}

Note-Given for two simple occurrence series, A and B. The table has one row for each occurrence time, $t_{\mathrm{a}}$, of $\mathrm{A}$ for which there is a concurrent or following occurrence of $\mathrm{B}$, at $t_{\mathrm{b}}$. Column $t_{\mathrm{A}}$ then shows $t_{\mathrm{a}}$, column $t_{\mathrm{B}}$ shows $t_{\mathrm{b}}$, and column $t_{\mathrm{B}}-t_{\mathrm{A}}$ the time distance $t_{\mathrm{b}}-t_{\mathrm{a}}$. The table is ordered after $t_{\mathrm{A}}$.

Table C2

Frequency Table for Distances

\begin{tabular}{cc}
$N$ & Distance \\
\hline 1 & 5 \\
1 & 8 \\
1 & 74 \\
\hline
\end{tabular}

Note-Distance is $t_{\mathrm{B}}-t_{\mathrm{A}}$, and $N$ its number of occurrences. This table is derived from Table C1. See Appendix C. 


\section{APPENDIX D \\ Category Definitions, Mostly From McGrew (1972)}

AUTOMANIPULATE. "(Initially divided into Finger and Fumble). Fingering is the use of the fingers, particularly thumb and forefinger, to manipulate part of one's body. It usually comprises scratching, rubbing, pinching, or otherwise handling the mouth, nose, ears, or hair. Finger is also oriented to the hands, arms, genitals, or anal region. Fumbling is similar movements directed to a small object (e.g., a jigsaw puzzle piece) or to a limited aspect of a large object (e.g., a screw on a wagon handle) . . . Auto-manipulation has two characteristic aspects: (1) it appears "unconnected" to other simultaneous body movement . . . ; (2) additional sensory modalities appear "disengaged." For example, the auto-manipulating child seldom looks at the fingered point" (p. 69).

CRAWL. "The body moves quadrupedally, usually forward, with the ventral surface off the ground. Various combinations of the limbs may touch the ground: palms, forearms, knees and toes, soles" (p. 108).

GLANCE-AT,PARTNER. Derived from McGrew's Glance, defined as "A rapid head movement which orients the face is followed by another head movement within three seconds reorienting the face" (p. 56).

GLANCE-AT,PICTCARD. See glance-at,partner (pictcard = picture card; see above).

GLANCE-AT,VIEWER. See glance-at,partner.

HAVE-VIEWER. The viewer is on the actor's side of the wall. Only beginnings are coded.

IMMOBILE. "Gross movement of the trunk, limbs, and head ceases for at least three seconds. Often the gaze is fixed. The fingers may continue to move, often in automanipulation, but the movements are restrained and inconspicuous" (p. 89).

KNEEL. "The trunk is lowered and tilted forward by hip and knee flexion, resulting in its resting on the knees (one or both) and feet (both). After assuming the posture, the trunk may be upright or maximally flexed at the hips with the head vertical and facing forward, or horizontal and facing down. When used as a resting position, the buttocks rest on the heels while flexion is 45 degrees or less. The forelimbs need not perform any supportive function" (p. 91).

LAUGH. "The characteristic sound is produced by a series of short, rapidly repeated, spasmodic, expiratory movements through the open mouth. This may be stylized into similar verbalizations of "Ha, ha, ha." It occurs in bouts, and individual elements are difficult if not impossible to define" (p. 60).

LIE. "The legs are fully flexed at the knees, then the arms are extended toward the ground and the trunk is tilted sideways; from the resulting seated position the trunk is further tilted, re- sulting in a sideways reclining posture with the main body axis horizontal to the ground. Alternatively, the legs are fully flexed, then the trunk is tilted forward into a prone reclining posture. From a seated position, the trunk is extended at the waist either sideways (preceded by extended arms), or backwards (not so preceded)" (p. 91).

LOOK-AT,PARTNER. Derived form McGrew's Look - that is, "The head is moved, re-orienting the face, and this orientation is maintained for at least three seconds" (p. 62). Here the target of the look is added (see also glance-at,partner).

LOOK-AT,PICTCARD. See look-at,partner.

LOOK-AT,VIEWER. See look-at,partner. The child looks at the viewer (which may be anywhere) but not into it, as in View (below).

MANIPUL, VIEWER. The child holds the viewer (toy) in her hands.

ORDER, VIEWER. Child verbally orders the other to give it the viewer (for example, "Give it to me!"). This behavior was observed very clearly from time to time in one of the children and seemed particularly relevant to the situation. Its highly predictable position in the temporal structure came, however, as a surprise. Only beginnings of this short behavior were coded.

PULL. "The arms are flexed toward the body, usually the chest, thus drawing an object or person toward the body or vice versa" (p. 80).

SIT. "The trunk is lowered by hip and knee flexion; the result is that the body rests primarily on the buttocks. While seated the legs may be extended horizontally, partially flexed with only the feet on the ground, or dangled. The neck is held extended with the head upright. Sitting may be maintained during locomotion, for example, when the buttocks are scooted along the ground" (p. 93).

STAND. "The trunk is raised by extension of the hips, knees, and back; the resulting posture is upright with both feet supporting the body's weight, about a shoulder's width apart. The arms usually hang free and the head is erect" (p. 95).

HEAD-TILT. "The head is moved sideways to an angle of approximately 45 degrees so the ear is closer to the shoulder" (p. 59).

VIEW,LONG. Look into the viewer for $3 \mathrm{sec}$ or more.

VIEW,SHORT. Glance into the viewer for less than $3 \mathrm{sec}$.

WALK. "The body moves bipedally forward at a moderate rate, alternating legs during each stride so that one foot is placed firmly on the ground before the other leaves the ground. The trunk is upright, and the arms swing forward and backward in unison with the opposite legs" (p. 112). 


\section{APPENDIX E \\ The Theme Program}

The Theme program has evolved over nearly 20 years (from a Fortran IV version to a Delphi version) and now consists of nearly one hundred thousand lines of source code. Therefore, no source code is included in this paper, but a free copy of the executable program for Windows $95 / 98 /$ NT can be downloaded (www.hi.is/ msm). In addition, at the time of this writing, a more powerful commercial version is being developed and will be announced at the above site.

Theme (first called Melody) takes its name from musical themes, but its development was also inspired by the so-called Expert Systems based on Artificial Intelligence (see, e.g., Hayes-Roth, Waterman, \& Lenat, 1983). It was initially partly intended for the analysis of existing parallel recordings (video + polygraph) of verbal, nonverbal, and physiological reactions (Cosnier, 1971, p. 93), as well as of facial action data scored with the FACS system (Ekman \& Friesen, 1978), but the first such study has just been reported (Schwab, 1999).

Theme is involved in a new multimedia course on the observational analysis of behavior (Dickins et al., in press).

\section{Data Collection}

The Theme software includes a specialized multimedia module for interactive coding of Theme type data (see the text) from digitized video recordings, so pattern detection can begin immediately after coding. This multimedia module can also find and play the video sections at which a selected pattern occurs. Moreover, the relevant types of data files collected by The Observer (Noldus, 1991; Noldus, Trienes, Hendriksen, Jansen, \&
Jansen, 2000) program are also being analyzed with Theme. Various other data formats have been easily transformed into Theme format for analysis.

\section{Pattern Detection}

Here is where all the T-pattern detection occurs, but this happens automatically, and only a few simple parameters are specified, such as the significance level and the minimum number of occurrences of detected patterns. The search algorithm is fast, so most of the time is usually spent with the next part of the software.

\section{Selecting and Analyzing Detected Patterns}

Patterns may be selected according to a number of criteria, such as their frequency, length (number of event types involved), or behavioral content - that is, the categories and/or event types it contains. And, for any selected (sub-) set of detected patterns, summary statistics can be obtained concerning, for example, the percentage of detected patterns that contain particular categories and/or event types or even combinations or sequences of categories and/or event types. This corresponds to asking whether such patterns were found in a way somewhat similar to the consultation of an Expert System, but such questions can, of course, be formulated as hypotheses. If any are found, the structure and behavioral content of these patterns can then be further inspected and analyzed. Note that this search/selection is quite different from the pattern detection phase, which must precede it. 